\title{
Making Mothers out of Grandmothers
}

\author{
${ }^{1}$ Palaniappan Narayanan, ${ }^{2}$ Lakshmanan Sakthikumar, ${ }^{3}$ Sivasundari Maharajan, ${ }^{4}$ Priyanka Mehta
}

\section{ABSTRACT}

Background: Almost 1 in 12,000 births result in a maternal cardiac arrest; the incidence of which is higher among women with factors such as hypertension, diabetes, hemorrhage, abnormal placentation, and advanced maternal age.

Case description: A 48-year-old primigravida, known hypertensive and diabetic and conceived by fetal embryo transfer was referred at 29 weeks and 1 day of gestation with painless bleeding P/V and was diagnosed with placenta previa. She was managed conservatively and given steroids for fetal lung maturity and magnesium sulfate for neuroprotection. She had a similar episode 10 days later, and 2 days after this, in the middle of the night she had profuse painless bleeding, and fetal heart rate of twin 2 was nonreassuring. The patient was taken up for emergency cesarean section and given general anesthesia. After delivery of the twins, the patient developed ventricular fibrillation. She was resuscitated within 3 minutes and monitored in the ICU. Both the twins were of low birthweight and admitted in the NICU. The patient gradually recovered and was discharged on postoperative day 9 . The babies were discharged 1 month after birth.

Conclusion: The cause of the ventricular fibrillation was multifactorial and involved autonomic imbalance, hypovolemia, the stress of advanced maternal age and comorbidities such as hypertension and diabetes mellitus.

Clinical significance: It is important to be aware of the etiology and management of a cardiac arrest and blood loss during pregnancy and labor. C-sections must be avoided as much as possible in an advanced maternal age group.

Keywords: Advanced maternal age, Cesarean section, Placenta previa, Ventricular fibrillation.

How to cite this article: Narayanan P, Sakthikumar L, Maharajan S, Mehta P. Making Mothers out of Grandmothers. J South Asian Feder Obst Gynae 2018;10(Suppl 1):347-350.

Source of support: Nil

Conflict of interest: None

Date of received: 6 July 2017

Date of acceptance: 12 April 2018

Date of publication: July 2019

\footnotetext{
${ }^{1}$ Professor and Unit Chief, ${ }^{2}$ Student, ${ }^{3}$ Associate Professor, ${ }^{4}$ Assistant Professor

${ }^{1-4}$ Department of Obstetrics and Gynaecology, Sri Ramachandra Medical College and Research Institute, Chennai, Tamil Nadu, India

Corresponding Author: Palaniappan Narayanan, Professor and Unit Chief, Department of Obstetrics and Gynaecology, Sri Ramachandra Medical College and Research Institute, Chennai, Tamil Nadu, India, e-mail: npalaniappan@hotmail.com
}

\section{BACKGROUND}

It was thought that the incidence of cardiac arrest during childbirth was around 1 in 30,000, but a multicentric study that analyzed data from more than 56 million hospital births in the United States, reported that almost 1 in every 12,000 births resulted in a maternal cardiac arrest. It was also concluded that the most common cause of cardiac arrest was excessive bleeding, the 2nd most common causes were heart failure and amniotic fluid embolism. The 3rd most common cause was sepsis and infections. ${ }^{1}$

Another study from Canada reported that hypertensive disorders of pregnancy, diabetes, diseases of the respiratory and nervous system, placental abnormalities and polyhydramnios were associated with cardiac arrest during labor. ${ }^{2}$

In another study, it was found that mothers with an advanced maternal age, who underwent a C-section were at a much higher risk of mortality $(2.56 / 10,000 \mathrm{vs}$. $0.44 / 10,000 ; p<0.01)$ and events such as cardiac arrest $(p<0.01)$. When compared to mothers with an advanced maternal age who had a normal vaginal delivery. It was concluded that a C-section must be avoided as much as possible in an advanced maternal age group. ${ }^{3}$

Accurate data on C-section rates or the incidence of cardiac arrest during labor in India are not available.

We are presenting the case of a recurrently bleeding placenta previa with many risk factors who developed ventricular fibrillation on the operation table. To the best of our knowledge, in most of the reported cases, it was either the cardiac arrest that led to a C-section or the cardiac arrest occurred postdelivery of the placenta and membranes (most commonly due to hemorrhage or amniotic fluid embolism) but our case is unique in the way that the cardiac arrest occurred postdelivery of the baby and before the delivery of the placenta.

\section{CASE DESCRIPTION}

A 48-year-old primigravida, a known case of hypertension on tablet labetalol $200 \mathrm{mg}$ BD for the past 3 years and overt diabetes mellitus on rapid insulin (4U-2U-0) for the past 9 months, carrying DCDA twins was referred to our institution at 29 weeks and 1 day of gestation with a chief complaint of painless bleeding $\mathrm{P} / \mathrm{V}$ for the past 7 hours. On perspeculum examination, $20 \mathrm{~g}$ of the clot was removed, no fresh bleeding was noticed. Transvaginal Ultrasound confirmed the presence of a placenta previa. 
Urine albumin was negative, and the patient did not present with any of the danger signs suggestive of preeclampsia or imminent eclampsia. BP charting was done once in 4 hours, sugars were checked 6th hourly.

The patient was managed conservatively (inj. tranexamic acid $500 \mathrm{mg}$ and later tab. tranexamic acid $500 \mathrm{mg}$ BD). She was started on tablet metformin $500 \mathrm{mg}$ $\mathrm{BD}$ because of high sugars.

The patient was conceived by fetal embryo transfer in 2016, dating scan at 8 weeks showed the presence of quadruplets and the fetal reduction was done to DCDA twins at 13 weeks of gestation. She continued taking labetalol $200 \mathrm{mg}$ BD for hypertension and rapid insulin (4U-2U-0) through the course of the pregnancy. She was given two doses of steroid for fetal lung maturity and magnesium sulfate for neuroprotection.

The patient had a failed IUI in 1998 (29 years old) and 2 failed fetal embryo transfers (2006-37 years old and 2010 — 41 years old). There was no significant menstrual, past, personal, marital and family history.

The patient was symptomatically better, and her hemoglobin was $11.7 \mathrm{~g} / \mathrm{dL}$.

Ten days later, the patient had bleeding $\mathrm{P} / \mathrm{V}$ which was painless. On perspeculum examination, $20 \mathrm{~g}$ of the clot was removed, and no fresh bleeding was noticed. The patient was medically managed with injection tranexamic acid $500 \mathrm{mg}$ IV TDS

High-risk consent was obtained. Preterm consent was obtained and counseling was given. Injection magnesium sulfate for neuroprotection and two doses of injection betamethasone 12 hours apart for fetal lung maturity was given. Transvaginal ultrasound showed that internal OS was closed, with anterior placenta $1.3 \mathrm{~cm}$ away and posterior placenta $1.7 \mathrm{~cm}$ away from the internal $\mathrm{OS}$ of the cervix. The patient's hemoglobin was $11.4 \mathrm{~g} / \mathrm{dL}$ two days after this. In the middle of the night, the patient had profuse painless bleeding $\mathrm{P} / \mathrm{V}, 30 \mathrm{~g}$ of the clot was removed on per speculum examination. The fetal heart rate of twin 2 was nonreassuring. A decision to carry out an emergency LSCS was made.

Mother was shifted to the OT at 1:45 am and because of a nonreassuring fetal heart rate and a recurrently bleeding placenta previa, she was given general anesthesia (propofol and scoline for muscle relaxation) with controlled ventilation. Her BP fell to $90 / 60 \mathrm{~mm} \mathrm{Hg}$. She responded to treatment with fluids and a bolus dose of vasopressors-phenylephrine.

The surgery was carried out and after delivery of twin 2 , the mother was administered 20 units of oxytocin in 500 $\mathrm{mL}$ of normal saline. Immediately after this, the mother developed a cardiac arrest on the table. ECG showed features suggestive of ventricular fibrillation. CPR was initiated, inj. adrenaline $1 \mathrm{mg}$ was given and DC shock of
$360 \mathrm{~J}$ was given; the patient was reverted to sinus rhythm within 3 minutes.

The placenta and membranes were delivered, and the surgery was completed.

Postcardiac arrest, high-risk consent was obtained, a central line was secured by the anesthetist, and two units of packed cells were transfused postoperative as hemoglobin was 6. Postarrest, ionotropic support was started (inj. adrenaline $0.1 \mu \mathrm{g} / \mathrm{kg} / \mathrm{min}$ ) and patient was shifted to the ICU and started on inj. furosemide infusion.

Twin 1 was a girl, weighing $1.21 \mathrm{~kg}$. Apgar score$5 / 10$ and $8 / 10$.

Twin 2 was a girl, weighing $1.08 \mathrm{~kg}$. Apgar score$5 / 10$ and $7 / 10$.

Both twins were of low birth weight and hence, monitored in the NICU. The twins were otherwise normal. They were fed with formula feeds.

Cardiologist opinion was obtained and Echo showed a left ventricle ejection fraction of $57 \%$ and a structurally normal heart. Baseline investigations were done, troponin $t$ and creatinine kinase levels were elevated.

Adrenaline infusion was tapered slowly, and furosemide infusion was stopped. The patient was extubated later, on the same day. Repeat Echo showed a left ventricle ejection fraction at $60 \%$ and the heart was structurally normal, troponin $\mathrm{T}$ was negative.

CBG monitoring of sugars and Bp monitoring was done.

\section{Postoperative Progress}

On postoperative day 1: Liquid diet was started. Because of low urine output, nephrology opinion was obtained. injection enoxaparin sodium (DVT prophylaxis) $0.4 \mathrm{~mL}$ SC BD was given for 3 days. $\mathrm{Hb}$ was $8.8 \mathrm{~g} / \mathrm{dL}$ and 3 units of red cells were transfused.

On postoperative day 2: Patient was shifted to the general ward. Babies were fed with expressed breast milk.

On postoperative day 4: Antibiotic coverage with inj. piperacillin + tazobactam and inj. metronidazole IV for 5 days. On postoperative day 5: Patient was started on tab. enalapril $5 \mathrm{mg}$ od and restarted on tab. metformin $500 \mathrm{mg} \mathrm{BD}$. The mother started to breastfeed her babies.

The patient was stable and hence, discharged on postoperative day 9 .

The babies were discharged from the NICU 1 month after birth.

\section{DISCUSSION}

There is a list of causes for a cardiac arrest to occur in a pregnant lady. The classification broadly includes anesthetic complications, accidents/trauma, bleeding, 
cardiovascular causes, drug-induced, embolic causes, fever, general causes, and hypertension. ${ }^{4}$

The risk factors in our patient were:

- Advanced maternal age

- Chronic hypertension-on labetalol

- Overt diabetes mellitus-on insulin

- Placenta previa

- Administered magnesium sulfate twice

- Preterm delivery

- Emergency LSCS

- General anesthesia and oxytocin.

Chronic hypertension is a state of decreased intravascular volume and hence, hypovolemia.

Labetalol is a sympathetic blocker and can cause an autonomic disturbance.

Diabetes, hypertension and advanced maternal age are known risk factors for abnormal placentation and decreased placental perfusion. This is confirmed the presence of a placenta previa and symmetric IUGR twins.

Recent studies suggest that insulin administration in chronic hypertensives has a detrimental effect on the heart and has the potential to increase blood pressure and precipitate cardiac failure. ${ }^{5,6}$

Studies suggest that cardiac arrest due to hemorrhage occur due to delays in recognition, treatment, or lack of care for women with obstetric hemorrhage. ${ }^{7-9}$ In some cases, hemorrhage may be concealed (e.g., abruption, retroperitoneal hemorrhage). The bleeding pregnant patient can lose $1500 \mathrm{~mL}$ of blood before any clinical manifestations of hypovolemia present. ${ }^{10}$ Occasionally, catastrophic hemorrhage can present abruptly or overwhelm standard therapies (e.g., amniotic fluid embolism). Eighty percent of obstetric hemorrhage is due to uterine atony, retained placenta, and abnormal placentation (placenta accreta, placenta previa, placental abruption), is an important etiology of massive hemorrhage. ${ }^{11-13}$

Magnesium sulfate is known to cause mild vasodilation, has tocolytic activity and is a CNS depressant. It is cardiotoxic and can cause a cardiac arrest. ${ }^{14,15}$

General anesthetic agents are potent peripheral vasodilators and decrease sympathetic nervous system activity. It can also cause myocardial depression and hypotension. ${ }^{16}$

Oxytocin is a potent vasodilator. It can also induce a QTc prolongation by indirect mechanisms. Oxytocin increases the duration of cardiomyocyte response and affects the autonomic nervous system tone. It can induce arrhythmias. $^{17}$

The physiologic changes in pregnancy such as an increased cardiac output, increased heart rate and increase in plasma volume by approximately $50 \%{ }^{18}$ play an effective role in masking the signs of hypovolemia and low hemoglobin (Flowchart 1).

\section{CONCLUSION}

In our case, the cause of the ventricular fibrillation is multifactorial. It is probably due to the combined effect of autonomic nervous imbalance (induced by the combination of labetalol, general anesthesia (propofol), oxytocin), hypovolemia (placenta previa, drug-induced vasodilation), an advanced maternal age which is not fully capable at putting up with the stress of pregnancy, and associated comorbidities such as diabetes and hypertension with a structurally normal heart.

Flowchart 1: Possible web of causation of cardiac arrest in this case

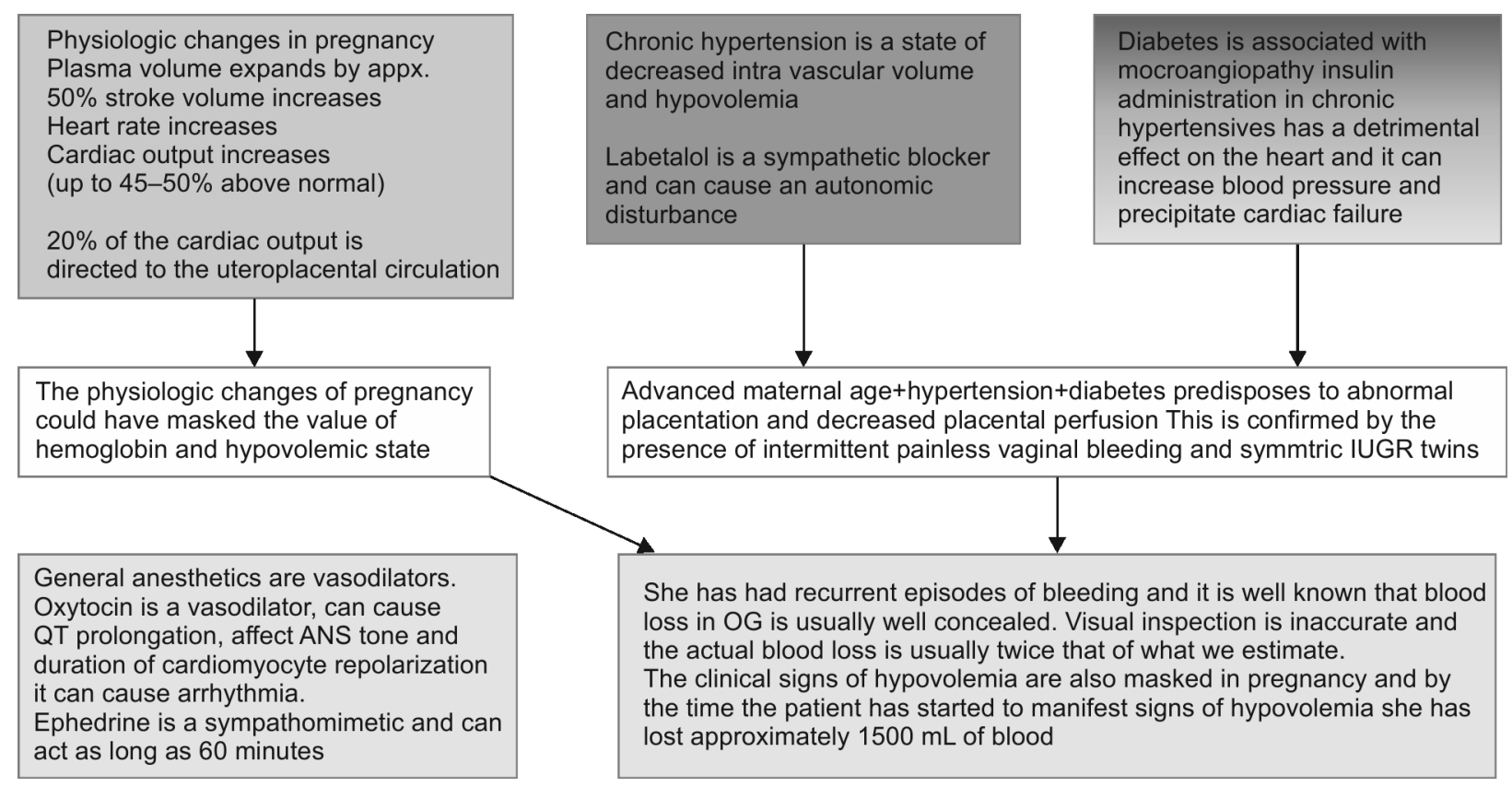


Having children is a boon, but however, age is a criterion for childbearing and child-rearing. Making mothers out of grandmothers is a paradox, and the future generation must be prepared to face this challenge.

\section{CLINICAL SIGNIFICANCE}

It is important to be aware of the etiology and management of a cardiac arrest and blood loss during pregnancy and labor. C-sections must be avoided as much as possible in an advanced age group.

\section{ACKNOWLEDGMENT}

Authors acknowledge the Department of Anesthesia, Critical Care Medicine, Cardiology and Nephrology for helping us manage this case.

\section{REFERENCES}

1. Mhyre JM, Tsen LC, et al. Cardiac arrest during hospitalization for delivery in the United States, 1998-2011. Anesthes 2014;120(4):810-818.

2. Balki M, Liu S, et al. Epidemiology of Cardiac Arrest During Hospitalization for Delivery in Canada: A Nationwide Study. AnesthAnalg. 2017 Feb 1 Published online 2017 Feb 1.

3. Lavecchia M, Sabbah M, et al. Effect of planned mode of delivery in women with advanced maternal age. Matern Child Health J 2016;20:2318-2327.

4. Jeejeebhoy FM, Zelop CM, et al. American Heart Association Emergency Cardiovascular Care Committee, Council on Cardiopulmonary, Critical Care, Perioperative and Resuscitation, Council on Cardiovascular Diseases in the Young, and Council on Clinical Cardiology. Cardiac arrest in pregnancy: a scientific statement from the American Heart Association. Circulation 2015;132:1747-1773.

5. Riehle C, Abel ED. Insulin signaling and heart failure. Circ Res 2016;118(7):1151-1169.
6. Persson SU. Blood pressure reactions to insulin treatment in patients with type 2 diabetes. The International Journal of Angiology: Official Publication of the International College of Angiology, Inc. 2007;16(4):135-138.

7. Centre for Maternal and Child Enquiries (CMACE). Saving Mothers' Lives: reviewing maternal deaths to make motherhood safer: 2006-08. The Eighth Report on Confidential Enquiries into Maternal Deaths in the United Kingdom. BJOG 2011;118(Suppl 1):1-203.

8. Della Torre $\mathrm{M}$, et al. Assessing preventability for obstetric hemorrhage. Am J Perinatol 2011;28:753-760.

9. Saucedo M, Deneux-Tharaux C, et al. Ten years of confidential inquiries into maternal deaths in France, 1998-2007. Obstet Gynecol 2013;122:752-760

10. Campbell TA, Sanson TG. Cardiac arrest and pregnancy. J Emerg Trauma Shock 2009;2:34-42.

11. Callaghan WM, Kuklina EV, et al. Trends in postpartum hemorrhage: United States, 1994-2006. Am J Obstet Gynecol 2010;202:353. e351-e356.

12. Bateman BT, Mhyre JM, et al. Peripartum hysterectomy in the United States: nationwide 14 year experience. Am J Obstet Gynecol 2012;206:63. e61-68.

13. Mhyre JM, Shilkrut A, et al. Massive blood transfusion during hospitalization for delivery in New York State, 1998-2007. Obstet Gynecol 2013;122:1288-1294.

14. Pryde PG, Mittendorf R. Contemporary usage of obstetric magnesium sulfate: indication, contraindication, and relevance of dose. Obstet Gynecol 2009;114:669-673.

15. Lu JF, Nightingale $\mathrm{CH}$. Magnesium sulfate in eclampsia and pre-eclampsia: pharmacokinetic principles. Clin Pharmacokinet 2000;38:305-314.

16. Akata T. General anesthetics and vascular smooth muscle: direct actions of general anesthetics on cellular mechanisms regulating vascular tone. Anesthes 2007;106(2):365-391.

17. Qu Y, Fang M, et al. Oxytocin does not directly alter cardiac repolarization in rabbit or human cardiac myocytes. Pharmacol Res Perspect. 2015;3:e00102

18. Alexander RH, Proctor HJ. Eds. Advanced Trauma Life Support, Course for Physicians. American College of Surgeons. Chicago, Illinois, 1993. 